\title{
The Voice of Canada's Front-line Pharmacists: CSHP Survey of Non-management Pharmacists
}

\author{
Michele Babich and Robin J Ensom
}

\section{INTRODUCTION}

$\mathrm{F}_{\mathrm{r} \text { o }}^{\mathrm{o}}$ any profession, competent, committed leadership reprents the difference between progress and extinction. Hospital pharmacy is no different. An editorial ${ }^{1}$ and a CSHP position statement ${ }^{2}$ on nonpharmacists in pharmacy leadership positions focused attention on a professional background in pharmacy as a prerequisite for senior managers in hospital pharmacy. However, being a pharmacist is far from the only necessary qualification. With an analysis based on the supplemental standard and learning objectives for residency training in pharmacy practice management of the American Society of Health-System Pharmacists, a pair of related articles considered the relative importance and self-evaluated skill level of current pharmacy managers. ${ }^{3,4}$ In addition, a survey of hospital pharmacy managers in Canada evaluated the contribution of various training programs in preparing hospital pharmacy managers for this role and provided demographic insight into the nature of hospital pharmacy management positions and their incumbents in Canada. ${ }^{5}$ Together, these studies created a useful framework for the identification and preparation of excellent hospital pharmacy managers, but there appears to be a shortage of one key ingredient: a pool of hospital pharmacist candidates interested in pursuing these management positions.

The survey of Canadian hospital pharmacy managers identified the positive aspects of their role, in the hopes that this knowledge would help in promoting these positions. ${ }^{5}$ This information has been used extensively in the subsequent preparation of action plans, education sessions, and promotional material. However, the survey analysis was barely complete when an intrinsic bias in the survey itself was identified: only pharmacists in management positions had been included. Another limitation of the survey was the potential difference in the values held by those in management positions and the pharmacists most likely to replace them. A crude analysis comparing the demographic characteristics of hospital phar- macy managers and staff pharmacists confirmed differences in the age and gender mix of these groups, ${ }^{6}$ but more specific information about the pharmacists who will be managers in the future is essential to developing an effective plan. The CSHP Hospital Pharmacy Management Task Force recognized this gap in understanding and recommended another survey, focusing on non-managers, to determine their demographic characteristics, interests, perceptions, and concerns about taking on formal management positions. ${ }^{6}$

This article describes the survey that we undertook in response to the task force recommendation and the interpretation of its results. The ultimate goal is to ensure that effective hospital pharmacy management continues into the future.

\section{METHODS}

A survey for non-managers was developed based on some of the questions in the survey of pharmacy leaders. ${ }^{5}$ The survey was initially drafted by a pharmacy student during her structured practical experience rotation at the CSHP national office in Ottawa. The survey (described in detail below) was reviewed, edited, and tested by members of the CSHP Hospital Pharmacy Management Task Force, which is composed mostly of hospital pharmacy managers with an interest in succession planning. The survey was developed in an online format to simplify the response mechanism. The survey tool used was Survey Monkey (www.surveymonkey.com). Responses were restricted to one reply per e-mail address to prevent multiple entries from the same person. Once a reply was received, the e-mail address was stripped from the data, and no other personal identifiers were collected, to ensure anonymity of responses.

An announcement about the survey was sent by e-mail to all CSHP members by the Society's national office on February 6, 2008. The original closing date was February 29, 2008, and an e-mail reminder was sent to all CSHP members 2 weeks 
before that date. The closing date was extended to March 21, 2008, to capture a larger sample size. The extension was communicated to all CSHP members on March 10, 2008, by means of a reminder e-mail.

The final survey consisted of 19 questions: 15 multiplechoice questions, 2 that required ranking of options, 1 that asked for details related to a previous question, and 1 open-ended question, to elicit any additional information. Most of the questions allowed the respondent to provide additional comments or expand on an option listed as "Other".

To capture only those CSHP members in non-management positions, the first question was, "What position do you currently hold?" If the answer was "management" (examples of which included manager, director, coordinator, and supervisor), the respondent was directed to the survey exit screen, where he or she was informed that the survey was seeking responses from non-management pharmacists only. All others were directed to the remainder of the survey.

The demographic questions elicited information such as type of position currently held, location of employment in Canada (by region), gender, full- or part-time status, years of practice experience, single-site or multisite responsibilities, and education and training background.

Descriptive data were tabulated and/or graphed as appropriate. Data for questions with the instruction "Select all that apply" were tabulated and sorted according to the number of individuals selecting each potential response. Ranked data were tabulated and sorted according to the number of respondents selecting each potential response in their top 5 . Comments were gathered and reviewed to identify common themes. No statistical analyses were performed. Because the fields within each survey were disconnected, correlations between different data elements could not be determined.

\section{RESULTS}

The final survey was distributed to 2812 CSHP members, of whom 839 initiated the survey, for a response rate of $30 \%$. The positions of these initial respondents were management (176 [21\%]), clinical specialists (144 [17\%]), staff pharmacists (470 [56\%]), residents (13 [1.5\%]), and students (36 [4.3\%]). Only the 663 non-managers were allowed to answer the rest of the questions.

\section{Demographic Characteristics}

Of the 663 respondents included in the analysis, 649 (98\%) indicated the region of Canada where they worked, and the distribution by region was similar to that of the 2010 CSHP membership (R. Rockwell, Membership Administrator, CSHP; personal communication, February 11, 2010) (Figure $1)$. The proportion of women was slightly higher among the survey respondents (497/645 [77\%]) than among the 2006 CSHP membership (72\%) (R. Rockwell, Membership Admin- istrator, CSHP; personal communication, March 13, 2007). Three-quarters of respondents were working full-time (497/663 [75\%]) and the remainder worked part-time $(166 / 663$ [25\%]). The breakdown by years of practice experience (649 respondents) was as follows: 140 (22\%) had less than 5 years' experience, $105(16 \%)$ had 5-10 years, $73(11 \%)$ had $11-15$ years, 100 (15\%) had 16-20 years, and $231(36 \%)$ had more than 20 years. The majority of respondents practised at one site (471/663 [71\%]), but a substantial proportion $(192 / 663$ [29\%]) practised at more than one site.

\section{Training and Interest in Management}

The respondents' education and training experiences are reported in Table 1. For a follow-up question asking whether their training had prepared them for a career in pharmacy management, most respondents answered in the negative. A majority of respondents (293/485 [60\%]) answered "yes" to the question "Would you be willing to take on additional training (i.e., a leadership program, master's degree, or doctoral degree) in order to better prepare yourself for a management position?"

When asked, "Have you considered taking on a management position?" $70(14 \%)$ of the 485 respondents to this question were currently interested in such positions, 154 (32\%) indicated possible interest in the future, 58 (12\%) had not considered it yet, and 149 (31\%) indicated that they would not want to take on a management position. Fifty-four $(11 \%)$ of the respondents answered "Other", many of them indicating that they had been in management positions before and had chosen not to continue in that role or that they had had negative experiences in management positions and would not return. A few indicated that their lack of interest was due to impending retirement.

Respondents' answers to the questions "What are the main duties of YOUR current manager?" and "Which of the following do you perceive would be the most rewarding part of pursuing a career in pharmacy management"? were compared with data from the previous survey of managers ${ }^{5}$ (Table 2). Similarly, ranked responses to the question "Which of the following are the main reasons you have not yet pursued a career in pharmacy management?" were compared with related data from the previous survey of managers ${ }^{5}$ (Table 3 ).

The majority of respondents (310/485 [64\%]) reported that the organizations for which they worked had positions that combined clinical and managerial duties, and a similar proportion (308 [64\%]) indicated that they would be interested in pursuing this option.

Only $6.0 \%$ of respondents (29/485) indicated awareness of the existence of succession plans in their organizations (either complete or in development); 225 (46\%) believed that there was no plan, and 231 (48\%) did not know. Among respondents reporting that a succession plan was in place, most 


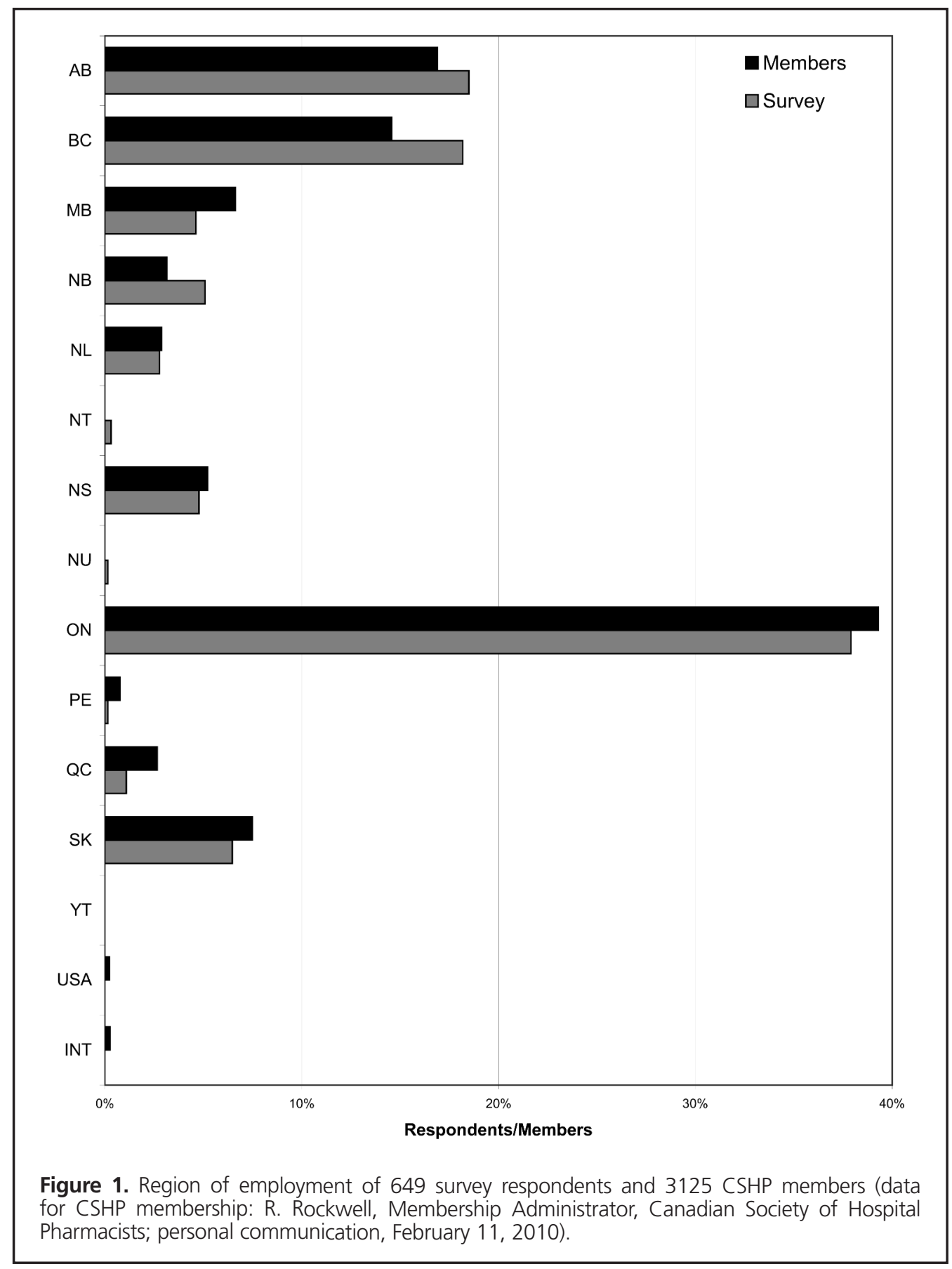

indicated that more intermediate managerial positions had been created to train people for higher-level positions in the future. Others indicated that certain individuals had been selected for further training to fill future positions.

The last question of the survey was open-ended and invited respondents to provide any further information that they thought was important for the CSHP Hospital Pharmacy Management Task Force to know. Ninety-two respondents provided further insights into the topic of future planning for pharmacy leadership (Table 4).

\section{DISCUSSION \\ Response Rate and Demographic Characteristics}

The distribution of responses across provinces and territories was generally similar to that for the CSHP membership, except for a lower response rate from Quebec. This might have been related to the fact that the survey was not available in French. The gender distribution of the non-management respondents was slightly more female-dominated than would have been 
Table 1. Education and Training of 485 Respondents to a Survey of Non-management Pharmacists

\begin{tabular}{lcccc} 
Education or training & Completed & In progress & \multicolumn{2}{c}{ Total No. (\%) } \\
\hline Bachelor's degree-pharmacy & 457 & 10 & 467 & $(96)$ \\
Bachelor's degree-nonpharmacy & 86 & 2 & $88(18)$ \\
Accredited Canadian Pharmacy Residency & 166 & 7 & $173(36)$ \\
$\begin{array}{l}\text { Administrative master's degree } \\
\text { (e.g., MBA, MHSc, MHSPh, MSc) }\end{array}$ & 13 & 9 & $22 \quad(4.5)$ \\
Clinical master's degree & 20 & 5 & $25 \quad(5.2)$ \\
Doctoral degree (e.g., PharmD or PhD) & 56 & 16 & $72 \quad(15)$ \\
Other & NA & NA & $40 \quad(8.2)$
\end{tabular}

$\mathrm{MBA}=$ master of business administration, $\mathrm{MHSC}=$ master of health science, $\mathrm{MHSPh}=$ master of health

science - pharmacy, MSc = master of science, NA = not applicable, PharmD = doctor of pharmacy,

$\mathrm{PhD}=$ doctor of philosophy.

Table 2. Perceptions of Positive Aspects of Management among 485 Non-management Pharmacists* and Hospital Pharmacy Managerst

\begin{tabular}{|c|c|c|c|c|}
\hline \multirow[b]{2}{*}{$\begin{array}{l}\text { Positive Aspect of } \\
\text { Pharmacy Management }\end{array}$} & \multicolumn{2}{|c|}{ Non-management Pharmacists (Staff) } & \multicolumn{2}{|c|}{ Pharmacy Managers } \\
\hline & $\begin{array}{c}\text { Most } \\
\text { Rewarding Aspects‡ } \\
\text { (Ranking) }\end{array}$ & $\begin{array}{l}\text { "Main duties of } \\
\text { your manager" } \\
\text { (Ranking) }\end{array}$ & $\begin{array}{l}\text { Most Positive } \\
\text { Aspects of } \\
\text { Current Position‡ } \\
\text { (Ranking) }\end{array}$ & $\begin{array}{l}\text { Most Important } \\
\text { Motivating } \\
\text { Factors } \\
\text { (Ranking) }\end{array}$ \\
\hline $\begin{array}{l}\text { Opportunity to participate in } \\
\text { decision-making }\end{array}$ & 1 & 3 & 1 & 1 \\
\hline Opportunity to influence pharmacy practice & 2 & 6 & 3 & 2 \\
\hline $\begin{array}{l}\text { Opportunity for innovation and } \\
\text { problem-solving }\end{array}$ & 3 & 4 & 2 & 3 \\
\hline Opportunity for personal growth & 4 & - & 5 & 6 \\
\hline $\begin{array}{l}\text { Getting the message out regarding the } \\
\text { role and contribution of pharmacists }\end{array}$ & 5 & 5 & 8 & 10 \\
\hline Opportunity to advance career & 6 & - & 4 & 13 \\
\hline Challenging work & 7 & - & 5 & 7 \\
\hline $\begin{array}{l}\text { Opportunity to help other people with } \\
\text { their professional development }\end{array}$ & 8 & 7 & 7 & 5 \\
\hline Opportunity for a variety of work & 9 & - & 6 & 8 \\
\hline $\begin{array}{l}\text { Opportunity to choose areas of personal } \\
\text { emphasis (autonomy) }\end{array}$ & 10 & - & 8 & 11 \\
\hline Salary progression or rate of pay & 11 & - & 9 & 12 \\
\hline Flexibility of position & - & - & 7 & 9 \\
\hline $\begin{array}{l}\text { Relationship with other areas of the } \\
\text { organization }\end{array}$ & - & - & 10 & 4 \\
\hline Interim step toward another career goal & - & - & 11 & 14 \\
\hline Financial or budget management & - & 1 & - & - \\
\hline Human resources & - & 2 & - & - \\
\hline
\end{tabular}

Dash = option not available for ranking.

*Current study.

tPrevious survey of hospital pharmacy managers. ${ }^{5}$

\#Each respondent was asked to rank his or her top 5 choices; rankings are based on overall responses.

expected from the CSHP membership, perhaps because the CSHP membership includes managers, a subgroup that has a higher proportion of men, ${ }^{6}$ whereas the survey excluded this group. The relevance of the difference in gender ratio between managers and non-managers was explored in more detail in the previous report of the CSHP Hospital Pharmacy Management Task Force. ${ }^{6}$

Most respondents who provided information about educational background had a bachelor's degree in pharmacy, with some having a residency and a few having administrative or clinical advanced degrees. Although it might be assumed that all Canadian pharmacists (and hence all respondents to the survey) would have a bachelor's degree, some respondents might have been students and others might have had a PharmD as their entry-to-practice degree. In addition, some of the respondents might have been graduates of a technical program, given that Memorial University of Newfoundland did not have a degree program until the mid-1980s. This mix 
Table 3. Perceptions of Negative Aspects of Management among 485 Non-management Pharmacists* and Hospital Pharmacy Managerst

\begin{tabular}{|c|c|c|}
\hline $\begin{array}{l}\text { Negative Aspect of } \\
\text { Pharmacy Management }\end{array}$ & $\begin{array}{l}\text { Staff Members' Main Reasons } \\
\text { for Not Pursuing a Career in } \\
\text { Pharmacy Management } \\
\text { (Ranking) }\end{array}$ & $\begin{array}{l}\text { Managers' Most Concerning } \\
\text { Factors about Accepting a } \\
\text { Management Position‡ } \\
\text { (Ranking) }\end{array}$ \\
\hline Concern about time commitment & 1 & 1 \\
\hline $\begin{array}{l}\text { Reluctance to deal with human } \\
\text { resource issues }\end{array}$ & 2 & 4 \\
\hline Reluctance to leave current position & 3 & 5 \\
\hline Family commitments & 4 & 3 \\
\hline $\begin{array}{l}\text { Concern about lack of support or } \\
\text { inadequate support for new managers } \\
\text { within organization }\end{array}$ & 5 & 6 \\
\hline $\begin{array}{l}\text { Lack of previous supporting education } \\
\text { for position }\end{array}$ & 6 & 3 \\
\hline Lack of experience in such a position & 7 & 2 \\
\hline Lack of financial rewards & 8 & 7 \\
\hline $\begin{array}{l}\text { Manager is overworked or does not speak } \\
\text { highly of her position }\end{array}$ & 9 & - \\
\hline No interest & 10 & - \\
\hline Lack of confidence in leadership abilities & 11 & 4 \\
\hline Recently graduated & 12 & - \\
\hline $\begin{array}{l}\text { Concern about reporting structure related } \\
\text { to position }\end{array}$ & - & 8 \\
\hline
\end{tabular}

Dash = option not available for ranking.

*Current study.

†Previous survey of hospital pharmacy managers. ${ }^{5}$

\#Each respondent was asked to rank his or her top 5 choices; rankings are based on overall responses.

Table 4. Selected Comments from Respondents, Categorized by Theme

Theme and Comments

No. of Responses

Additional educational opportunities $(n=20)$

$\begin{array}{ll}\text { Structured mentorship is important } & 10\end{array}$

Leadership development opportunities are important

University curriculum should include courses on managerial effectiveness, time management

Offer CSHP continuing education for managers in training or certificate training; have pharmacist managers do the teaching

Offer online education program; promote leadership education

Develop and offer a management residency program

\section{Respect for current managers $(n=32)$}

Have managers who are leaders (people whom others look up to, respect, and want to follow); lack of respect for leadership positions

Bring in leaders who are more in tune with current practice models

Issues with nonpharmacist managers influence staff pharmacists' interest in management positions (4 respondents reported a negative influence and 1 reported a positive experience)

\section{Other $(\boldsymbol{n}=\mathbf{2 2})$}

Too close to retirement to consider management position

1

5

2

24

3

5

Too much stress, thankless or endless job

Combination of management and clinical jobs not possible; clinical loses out

Need more intermediate supervisor/manager positions

PharmD training does not provide what is needed to be an effective manager

Financial issues related to obtaining more education, even though additional education is seen to be necessary 
of educational background, dominated by bachelor-level training, was not surprising for respondents in non-managerial positions, although those with administrative degrees represent potentially untapped, well-educated human resources for leadership roles.

\section{Limitations}

The survey did not allow us to correlate responses from different questions as a way of delving deeper into the relations among demographic characteristics, education, and interest. Such correlations may represent fertile ground for further investigation. In addition, the survey was limited to CSHP members. Given that not all Canadian pharmacists are members of the Society, the interpretation of the survey results may be generalizable only to those who are CSHP members.

\section{Reasons for Optimism}

Nearly half (46\%) of respondents indicated that they were currently interested in a management position or might be interested in the future. In a seperate question, more than half (60\%) would be willing to take in additional training to prepare for a management position. The survey may have had an unknown level of self-selection bias, with those having an interest in management being more likely to respond. Nonetheless, these expressions of potential interest represent an untapped wealth of motivation and desire to which current leaders need to pay attention in succession planning. If any significant proportion of these individuals follow through on their interest, there would be more than enough pharmacists to fill the management positions that are likely to become available.

Table 2 clearly identifies many commonalities in the factors that motivated the current generation of hospital pharmacy managers to take up their positions and those that interest current staff pharmacists who might become managers in the future. Opportunities to influence pharmacy practice, to participate in decision-making, to exercise innovation and problem-solving skills, and to achieve personal growth were rated highly by both groups. Furthermore, the fact that managers rated 3 of these as the most positive aspects of their pharmacy management positions indicates alignment of motivation and reality. It is notable that many hospital pharmacy managers reported that their aspirations in taking on a management role had been rewarded. Shallen Letwin, former president of CSHP, expressed this alignment well in the title of one of his presidential officer's reports: "Hospital Pharmacy Management-What a Career!"” The fact that the current cadre of hospital pharmacy managers has achieved this kind of fulfillment may encourage the next generation, who have indicated that they have similar aspirations. Furthermore, the factors rated lowest suggest that pharmacists are less interested in personal gain than in altruistic reasons for pursuing management positions.
Table 3 also shows similarities between current managers and staff pharmacists in terms of concerns about accepting or pursuing hospital pharmacy management positions. Lack of previous supporting education, lack of previous experience, the time commitment required, existing family commitments, and reluctance to leave one's current position were of concern to both groups, yet the current managers have obviously overcome these challenges. We expect that as current staff pharmacists enter into management positions, they will also be successful in dealing with these issues. This adaptation could be supported by having current managers provide coaching and mentoring to new managers.

The good match between the number of mixed clinical management positions available and staff pharmacists interested in this type of position suggests that we are already creating the kind of management positions that will appeal to many of our staff. The fact that almost $30 \%$ of respondents reported practising at more than one site may give them valuable experience in the multisite organizational issues critical to many leadership positions today. Cultural and team-building issues would be common to those multisite organizations and could be used in mentoring and coaching future leaders. Clinical practice at more than one site provides the appropriate background for this type of training.

\section{Reasons for Concern}

For the vast majority of staff pharmacists who responded to the survey, the sole qualification for pharmacy practice was a bachelor's degree in pharmacy. Respondents indicated that this degree did not prepare them for a career in management. This represents a real and significant gap between existing preparation and perceived need. Axworthy and MacKinnon ${ }^{3}$ found that formal management training reduced the gap between the relative importance of various aspects of management and the self-evaluated skill level of current pharmacy managers. It follows that management training remains an unfulfilled need.

Staff pharmacists had the perception that hospital pharmacy managers are mainly involved in the 2 areas of financial and budget management and human resources. However, these aspects of the job were not on the list of things that attract staff pharmacists to management positions. This mismatch may be critical, as it could discourage staff from pursuing management positions. This finding is in agreement with that of Axworthy and MacKinnon, ${ }^{3}$ who reported that some of the greatest discrepancies between relative importance and self-evaluated skill level of current pharmacy managers lay in the areas of financial and human resource issues. Clearly, these 2 categories of issues represent a challenge for existing managers and a potential deterrent for staff pharmacists. 
Another concern arising from this survey was the finding that managers' influence on pharmacy practice was ranked sixth in terms of respondents' perceptions of the duties of managers. Since this influence is often a pharmacist's primary motivation to seek a management position, this perception could be very discouraging to management aspirations. Salary was not considered one of the top rewarding aspects of hospital pharmacy management and therefore is unlikely to compensate for perceived lack of influence.

A substantial number of responses indicated that current pharmacists did not respect the role of managers, for a variety of reasons. A number of other comments expressed the view that the manager's role was undesirable because of the required time commitment and stress. As such, it should come as no surprise that staff pharmacists are not eagerly pursuing management positions.

Regionalization, accompanied by the flattening of organizational charts, may be further undermining the desirability of management positions and impeding the preparation of senior pharmacy managers. Although pharmacists are interested in management positions because of opportunities to influence pharmacy practice, to participate in decision-making, and to exercise innovation and problem-solving skills, the centralized decision-making that results from regionalization may frustrate those aspirations. Managers are often expected to implement rather than decide. Simultaneously, the creation of large regions leads to focused management positions that develop pharmacists' skills and abilities in specific areas such as medication safety, medication-use management, education, operations, sterile production, and technology. However, the pharmacists who take up these positions may not develop the broad insight into all aspects of hospital pharmacy that is a prerequisite for the most senior pharmacy management positions.

\section{Recommendations for the Future}

Succession planning has been identified as a critical strategy for recruiting and retaining future pharmacy leaders. ${ }^{8}$ However only $29(6.0 \%)$ of the respondents to this survey indicated that such a plan was in place for pharmacy management in their respective departments. The remainder were almost evenly split between those reporting that no plan was in place (46\%) and those who did not know whether their departments had a plan (48\%). This supports the previously reported finding that almost three-quarters of respondents to the survey of managers ${ }^{5}$ acknowledged that there was no succession plan in place. These data represent a large gap between current status and what is needed to prepare for the future. Clearly, succession planning must be high on our communal "to-do" list. Each organization must develop its own succession plan, which should include looking at its demographics, the current formal and informal education level of its staff, what is required in terms of future positions, and what current staff values may include. When preparing succession plans, it may be worth remembering that one-quarter of the respondents to our survey were working part-time, representing a substantial workforce that may have differing needs and values as they relate to leadership positions.

Although current managers have overcome concerns about taking on a management role, we need to develop strategies to introduce staff pharmacists to management roles, so that they gain comfort and insight into the real experience. It has been suggested that temporary positions or filling in during absences of management staff might allay some fears in this regard. ${ }^{6}$ Alternatively, the current survey results suggest that more pharmacists would consider a mixed management-clinical role than are interested or possibly interested in a management role. In addition, a number of respondents' comments suggested that they were very satisfied with their involvement in clinical practice and would not want to give that up. This suggests that we may be effective in enticing staff into management positions if those positions incorporate a clinical role. Only the future will tell if these mixed roles become the norm, as seems to be the case for medicine, or if they will lead to focused management positions.

The bachelor's degree in pharmacy is not effective preparation for a management role, yet a good proportion of respondents did not feel that they lacked confidence in their leadership abilities. It will be important to develop a strategy to train, mentor, and motivate these individuals for the positions they want and that we need to fill. In 2002, Axworthy and MacKinnon $^{3}$ noted that, "Failure to do so [find a way to bridge the potential management education gap] would ignore the needs identified in this study and could have detrimental effects on health-system pharmacy practice in Canada." As of yet, we do not appear to have heeded this warning and must actively advocate for programs to fill the gap. In addition, both surveys pointed to mentorship, coaching, and opportunities to gain experience and support from current pharmacy leaders as being critical to success. Informal surveys of graduating pharmacists have also indicated the increasing importance of mentorship as a desirable characteristic of future employers. It is fortunate that there is a large, easily identifiable cadre of such mentors who have been recognized as Fellows of CSHP. It will be important to engage them and other CSHP members with the skills and interest to be mentors in an effort to help the managers of the future prepare to take their place.

\section{CONCLUSIONS}

The results of this survey of non-management pharmacists in Canada yielded encouraging information about the number of respondents who are interested in pursuing a management career. Therefore, it is not for lack of interest that we may be facing a critical shortage of hospital pharmacy managers in the 
future. Instead, the path to a management career that is laid out for current pharmacists may be the biggest impediment.

Together, the survey of non-management pharmacists reported here and the survey of hospital pharmacy managers reported previously ${ }^{5}$ have provided great insight into the similarities and differences between hospital pharmacy managers and their staff. There is certainly room for optimism about the potential of staff pharmacists to take on management positions as they become available, but there is no room for complacency. Clear markers are available to guide us in preparing for the future, but we must take action now to ensure that the promise of the next generation of hospital pharmacy managers is fulfilled.

\section{References}

1. MacKinnon NJ, Clark S, McCaffrey KJ. Storm clouds on the horizon: the future of hospital pharmacy management [editorial]. Can J Hosp Pharm 2005;58(5):261-262.

2. Canadian Society of Hospital Pharmacists. The role of the pharmacist as head of hospital pharmacy services. Can J Hosp Pharm 2005;58(5): 299-303.

3. Axworthy S, MacKinnon NJ. Perceived importance and self-assessment of the skills of Canada's health-system pharmacy managers. Am J Health Syst Pharm 2002;59(11):1090-1097.

4. Faris RJ, MacKinnon GE 3rd, MacKinnon NJ, Kennedy PL. Perceived importance of pharmacy management skills. Am J Health Syst Pharm 2005;62(10):1067-1072.

5. Musing ELS, Wong M, Jackson L, Lee J, Slote C. A focus on leadership: CSHP's 2007 national leadership survey. Can J Hosp Pharm 2008; 61(1):70-77.
6. CSHP Hospital Pharmacy Management Task Force. Planning for hospital pharmacy management, now and in the future. Can J Hosp Pharm 2008;61(5):374-384.

7. Letwin S. Hospital pharmacy management-what a career! Can J Hosp Pharm 2007;60(5):351.

8. White SJ. Effective pharmacy department leadership. Hosp Pharm 2007; 42(1):77-79.

Michele Babich, BScPharm, MHSA, is Director of Pharmacy Services, Vancouver Island Health Authority, Victoria, British Columbia.

Robin J Ensom, PharmD, FCSHP, is Corporate Director, Medical and Clinical Support Services, Providence Health Care, Vancouver, British Columbia.

Address correspondence to:

Dr Robin J Ensom

Providence Health Care

1081 Burrard Street

Vancouver BC V6Z 1Y6

e-mail: rensom@providencehealth.bc.ca

\section{Acknowledgements}

We thank Sarah Miller, who at the time of conducting the survey was a pharmacist student from the University of Saskatchewan completing a Structured Practical Experience Program rotation at the CSHP National Office, for her assistance in designing the survey. We would also like to express our appreciation to Emily Musing and her coauthors for generously sharing the raw data from CSHP's 2007 national leadership survey. The survey reported here arose from discussions within the CSHP Hospital Pharmacy Management Task Force, of which the coauthors were members.

\section{CISADL 2010}

Order your copy of the 2010 Canadian Investigational \& Special Access Drug List today!

Please use the CSHP order form found online to place your order:

\section{http://www.cshp.ca/productsServices/otherPublications/canadianlnvestigational e.asp}

The CISADL is a compilation of drugs that are currently not marketed in Canada and may have Investigational or Special Access status with Health Canada. This list is not endorsed by Health Canada's Special Access Program. For precise information about the regulatory status of a drug, contact the Special Access Program directly. Entries to the list are contributed to by several Drug Information Centres across Canada and by Canadian drug manufacturers. In cases where non-marketed drugs do not appear on the list, foreign references should be consulted. The content of the list includes generic name and strength/concentration, dosage form, pharmacology/therapeutic use, trade and code name, source (manufacturer/distributor), and comments. Available in English only.

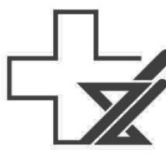

